\title{
Developing an Optimal Method for Multi-asset Portfolio's Downside Protection
}

\author{
Igor Gvozdanovic ${ }^{1 *}$ and Rajagopal Ramamoorthy ${ }^{2}$ \\ ${ }^{1}$ Zagreb School of Economics and Management, Zagreb, Croatia, SMC University, Zug, Switzerland \\ ${ }^{2}$ SMC University, Zug, Switzerland
}

\begin{abstract}
This qualitative research based on phenomenology might prove useful in writing the Investment Policy for Institutional Investors in nascent capital markets. The study provides insight into how institutional investors prepare for imminent occurrence of extreme market conditions and the measures they adopt to mitigate the consequences of such extreme market conditions on their investment portfolios. The responses were collected over nearly one and a half years, from March 2013 to September 2014, using various forums held in different cities of the world. The study adopted the methodological triangulation approach to reinforce the findings and build credibility whilst enhancing the usefulness of the findings. This was done by interacting with different groups of respondents and different forums to confirm the findings. All of the respondents were senior decision makers from a wide variety of Institutional Investment entities. From the detailed analysis of the responses emerged concise but dominant topics and strategies. Some of these include risk-based diversification, volatility regimes and risk indicators, low volatility anomalies, rebalancing, going long volatility, longer horizon, rule-based decision making and corporate governance, counter-cyclicality, benchmark agnostic strategies and valuation fundamentals.
\end{abstract}

Keywords: Investment policies; International investors; Forecasting; Extreme market conditions; Senior decision makers; Volatility; Institutional investment; Volatility regimes

\section{Background}

For a portfolio manager, one of the most important tasks is to make sure the portfolio value does not fall drastically under extreme market conditions. The manager's skill is evident in his/her ability to protect as much downside as possible (Schroders Investment Managment Ltd., [1]) when faced with extreme market conditions. Several methods have been proposed for reducing downside risk to the minimum during crisis situations, similar to 1987 and 2008. Program trading and index arbitrage [2] were strategies that had gained some popularity prior to the market crash in 1987, however, this failed during the 1987 market crash. Option based portfolio insurance [3] and "constant proportion portfolio insurance" (CPPI) [4], that uses volatility products such as VIX based products [5], were strategies that gained some credence during the crisis in 2008. However, under extreme market conditions, such as occurred 1987 and 2008, there has been no optimal solution for a multi-asset portfolio downside protection. Hyung and De Vries [6] have divided downside risk into part attributable to the markets, part to idiosyncratic risk, and an independent factor. Xiong and Izdorak [7] have explored alternatives to "Mean-variance-optimization" (MVO) that incorporates non-normal return distributions. Mirza and Lars [8] have studied several acknowledged downside risk measures extensively and compared them with variances. A few trillion dollars have been wiped out of investment portfolios market values [9], for instance, when market capitalization decreased significantly as a consequence of the market moves during 2008, albeit not even the best of investors have escaped the onslaught of the severity of the market conditions. Hence, trying to understand this risk, considering the practical implications of this risk on portfolios and asset values, and to consider suitable practical measures to alleviate the effect of such extreme market conditions (if not eliminate them), may contribute in a small way to more efficient portfolio management. It is also important to recognize that such strategies, used for obtaining downside protection under extreme market conditions, should have minimal detrimental effects on the portfolios during intervening years when markets perform normally. Papaioannou, Park, Pihlman, and Hoorn [10] claim that during a financial crisis, institutional investors tend to exhibit a herding behavior that is; they tend to adopt procyclical investment strategies, which tend to accentuate the fragility of the already weak financial systems. This pro-cyclical behavior by institutional investors has been, and will continue to be, the major cause of extreme market downturns. A lax monetary policy with low interest rates for a protracted period, which occurred before the subprime crisis unfolded, caused institutional investors to augment their risk appetite to the extent that it created considerable side effects, namely an underestimation of liquidity risks and credit risk. Although herd behavior has been observed prior to the current financial crisis, its effects were much more harmful during market down turns. This, to a great extent, was a result of the realization that the imbalance that had grown into the system could not be sustained. These disparities in the system began to unravel quickly in an unruly manner [11].

\section{Purpose of the Research}

This study explores the causes and consequences of large portfolio draw-downs of Institutional Investments, with the intent of developing a suitable method for reducing and possibly mitigating such extreme draw-downs. Tail-risk hedging involves adopting measures to mitigate the extreme market conditions, purchasing insurance, or of changing the asset allocation, to limit the impact of tail-risk. Figure 1 shows the occurrence of tail-risk events in the S\&P 500, that is, events with two or more standard deviations.

Our research also shows why long term investors are different in terms of their risk mitigation practices from investors who may need to fulfill short term liabilities. Similarly to our findings, seminal research

*Corresponding author: Igor Gvozdanovic, Zagreb School of Economics and Management, Zagreb, Croatia, SMC University, Zug, Switzerland, E-mail: igor.gvozdanovic@swissmc.ch

Received May 06, 2016; Accepted May 17, 2016; Published May 25, 2016

Citation: Gvozdanovic I, Ramamoorthy R (2016) Developing an Optimal Method for Multi-asset Portfolio's Downside Protection. Int J Econ Manag Sci 5: 347. doi:10.4172/2162-6359.1000347

Copyright: (c) 2016 Gvozdanovic I, et al. This is an open-access article distributed under the terms of the Creative Commons Attribution License, which permits unrestricted use, distribution, and reproduction in any medium, provided the original author and source are credited. 


\section{S\&P 500 Annual Returns (1926 - 2010)}

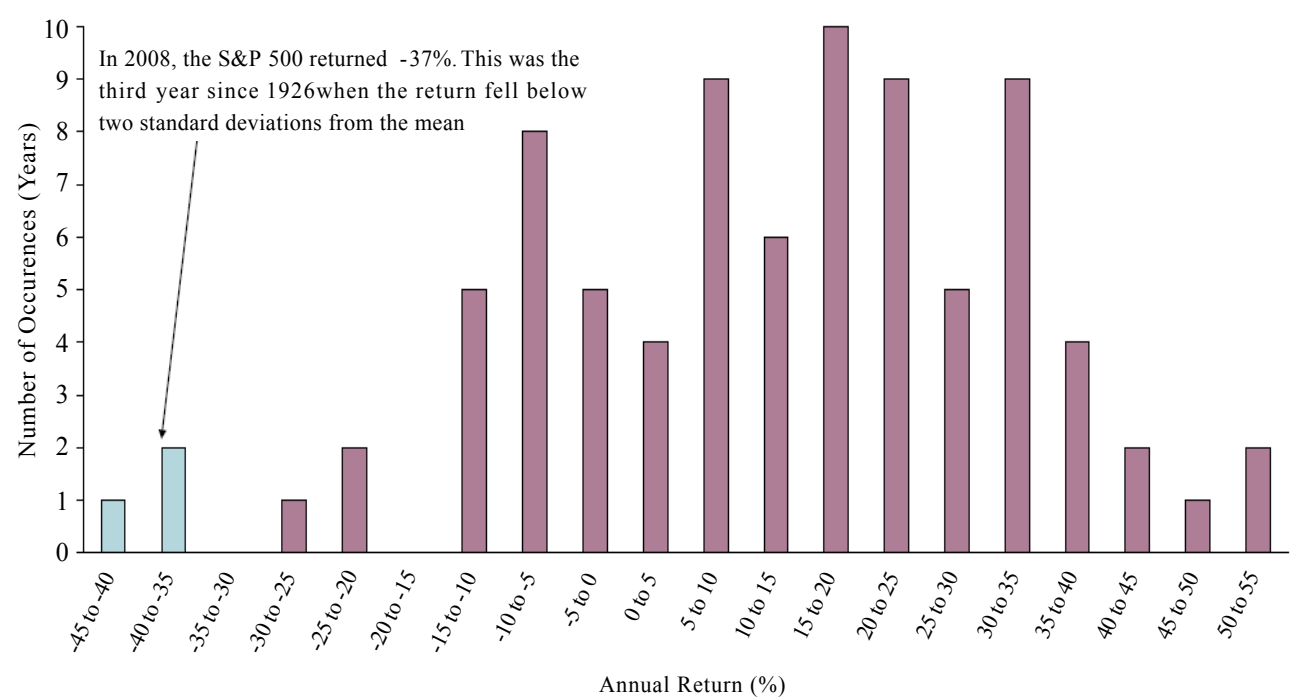

Figure 1: S\&P 500 Annual Returns. Reprinted from Tail Risk Management by Kinniburgh, Source:February 1, 2012.Retrieved from http://ssrn.com/abstract=2247467.

by Ang et al. [12] suggests that long term institutional investors should probably have a very different perspective to draw downs due to extreme market conditions; in fact, due to its long term nature such institutions should benefit from selling insurance against such drawdowns. Our study further delves into discovering what specific steps, tasks, and decisions need to be made by institutional investors to mitigate or minimize the effects of extreme market conditions. To do that, the study explores how extreme market conditions result in large draw downs and explore mitigating measures and steps that could be adopted.

\section{Research Design and Methodology}

We applied a qualitative methodology with a phenomenological design because the purpose of the study is to gain an understanding of the practical implications of extreme market conditions. This involves understanding of how investors forecast the probability of extreme market conditions and the time of these occurrences, using risk indicators, equity market valuations, correlation of asset returns, signs of imminent recession, inverted yield curves, and several other signs and indicators. It also involves assessing the effect of the extreme market conditions on portfolios and what measures could mitigate the negative consequences. Data was collected using personal interviews, group discussions, online forums, and written questionnaires while ensuring the researcher's own views remained "bracketed", that is, ensuring that researcher bias was avoided. Semi-structured interviews of 20 institutional investor representatives were conducted in line with Masons' guidelines for sample size in qualitative research [13]. The interview volunteers were mainly senior decision makers including: Chief Investment Officers, Managing Directors, CEO's, and other strategic decision makers. Every effort was made to conduct face-toface interviews with such decision makers, some telephonic interviews also had to be conducted since this was also a useful data source. The Questionnaire also was forwarded by email to willing participants and the responses were discussed with the respondents. Extensive notes were taken during the interviews and more importantly audio recordings of the interview sessions were made. Transcription was done as quickly as possible to avoid losing any crucial information and thoughts of the interviewee or respondents.

The Institutional Investors Network (IIN) arranged for interviews with crucial decision makers during the IIN Roundtables in London in May 2013. This Roundtable was a congregation of important decision makers from sovereign wealth funds, pension funds, Central Banks and other institutional investors (e.g., development agencies and banks). The IIN also allowed the use of a secure site accessible only to genuine institutional investors, where members could address issues relating to institutional investors. The questions to be addressed in the interview were posted on the site in advance along with information on the research interests. This was done mainly to give comfort and confidence to respondents, of the genuine nature of the research interests. This also ensured that the data and information is not being used for promoting any products or services to the members of the forum. Arrangements were made with the Global Alternative Return Congress, held in the third week of May 2013, to provide introductions to willing participants in the interviews. This is a forum of institutional investors involving senior decision makers.

Interviews were conducted with decision makers at Institutional Investors in Dubai and Abu Dhabi. This was an "exploratory phase" where Pilot interviews were conducted and the data collected from such interviews were revised based on the logic of theoretical sampling. This was done mainly to assist in addressing more focused questions, which may be either narrowed or broadened in a particular direction [14]. Interviews focused on the measures Institutional Investors have taken, considered, or would pursue in the future to protect against "downside risk". The following information was obtained in advance, in other words, before the interview, through document analysis, or during the interview by asking relevant questions:

- Fund size, and its characteristics including invested asset classes (both tactical and strategic allocation);

- The investment sophistication capabilities of the investors 
(once assessed, appropriate questions were formed to extract this information); and

- The role of the Investment Committee, Risk Committee functions, and other decision makers.

The methodology involved in obtaining information related to:

- The process of escalation of issues related to overall risk management;

- The authorizations required for making decisions and taking appropriate and timely measures to protect the downside of the portfolios.

The interviews endeavoured to obtain information regarding to:

- Practical measures considered and taken for downside risk,

- Protection (if any) for both post and pre extreme market conditions,

- Results of measures taken and its implications for the future, and

- Recommendations and suggestions they may wish to make with regards to portfolio downside protection.

\section{Research Questions}

The research questions on which the study provides answers through newly gathered data and results obtained are the following:

a. What practical measures can institutional investors consider/ take to alleviate the effects of significant market events?

b. What measures have investors implemented through the years to avoid the consequences of extreme market conditions and how have they provided downside protection?

c. What are the tools currently available for tail-risk hedging and to protect investors against "extreme market conditions"?

d. What protection does "tail risk hedging" provide for protection against extreme market conditions observed in 2008 and 1987?

e. How can alternative investments, that is, hedge fund strategies, be used to obtain portfolio downside protection?

\section{Demographics of Respondents}

The phenomenology based qualitative analysis was initiated in May 2013 with the Data collection process and was completed sometime in March 2014. This process involved interviewing more than 30 willing professionals (Table 1 and Figure 2, Demographics of the Respondents for the Research Study) from the financial investment industry and collecting data from various sources and forums. The respondents included Chief Executive Officers, Chief Investment Officers, and Chief Risk Officers, Head of Investment Departments, Controllers, and other decision makers in the financial investment industry. Most of the institutions they are employed with have a diversified asset allocation. The respondents and survey participants were from different parts of the world representing very large Institutional Investors from the U.S., Canada, UK, Australia, Sweden, Denmark, Netherlands, Switzerland, Singapore, Brazil, United Arab Emirates, Sudan, Kuwait, Oman, New Zealand, and the United Nations (Table 1 and Figure 2).

\section{Additional Topics that Emerged from the Study}

1. Institutional Investors need to manage their liquidity
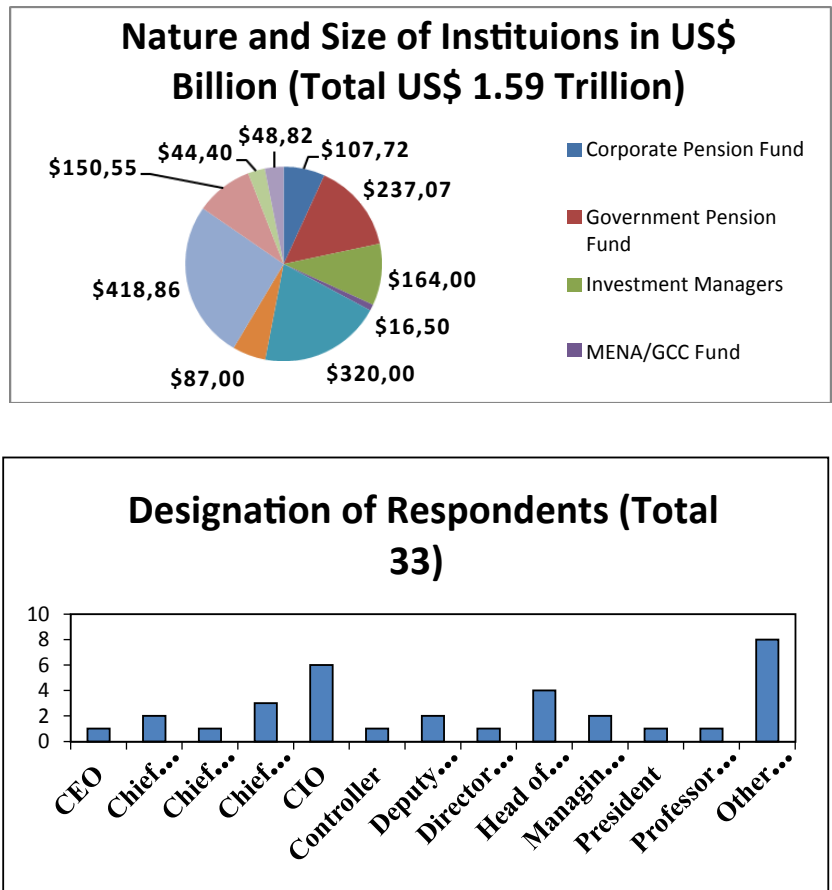

\section{Country representation in US\$ Billion (Total US\$ 1.59 Trillion)}

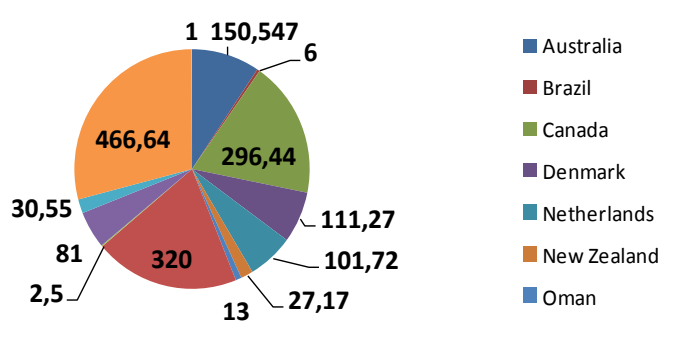

Source: Authors

Figure 2: Pie Charts elucidating demographics of the Respondents to the study.

requirements based on their liabilities. A long term perspective will help strategic asset allocation.

2. A dynamic asset allocation approach and optimal diversification is crucial.

3. Real Assets are considered by many investors as amongst the best hedges against tail risks.

4. Adhering to Strategic benchmarks will risk riding the bubbles of the benchmark and enforcing relative performance on the manager as an agent.

5. An educated well informed board that is taken into confidence and hence is highly supportive of the management is crucial for handling crisis situations.

6. Tail risk hedging using options, insurance in any form in extreme market conditions is generally considered an impractical strategy by institutional investors although there are exceptions. 
Citation: Gvozdanovic I, Ramamoorthy R (2016) Developing an Optimal Method for Multi-asset Portfolio's Downside Protection. Int J Econ Manag Sci 5: 347. doi:10.4172/2162-6359.1000347

Page 4 of 5

\begin{tabular}{|c|c|c|c|}
\hline \multicolumn{4}{|c|}{ Respondents for the Research Study } \\
\hline Nature of Institution & Design & Country & Assets Under Management \\
\hline & & & US\$ Billion \\
\hline Corporate Pension fund & Sr. Investment Officer & Brazil & 6 \\
\hline Corporate Pension fund & Sr. Investment Strategist & Netherlands & 74.55 \\
\hline Corporate Pension fund & $\mathrm{ClO}$ & Netherlands & 27.17 \\
\hline Corporate Pension Fund Total & & & 107.72 \\
\hline Government Pension Fund & Chief Risk Officer & Denmark & 111.27 \\
\hline Government Pension Fund & Head of Port folio Design & New Zealand & 14.25 \\
\hline Government Pension Fund & Chief Investment Strategist & Sweden & 40 \\
\hline Government Pension Fund & Dy. CEO & Sweden & 41 \\
\hline Government Pension Fund & $\mathrm{ClO}$ & Switzerland & 30.55 \\
\hline Government Pension Fund Total & & & 237.07 \\
\hline Health Research Foundation & Controller & UK & 0.7 \\
\hline Pension Investment Manager & Senior Vice President & Canada & 94 \\
\hline Institutional Investment Manager & VP Risk Management & Canada & 70 \\
\hline Investment Managers Total & & & 164 \\
\hline MENA/GCC Sovereign Wealth Fund & Chief Economist & Oman & 13 \\
\hline Africa Infra Structure Development Base & Director General & Sudan & 2.5 \\
\hline Multi-Lateral Development Fund & Head of Invest. Management & UAE & 1 \\
\hline MENA/GCC Fund Total & & & 16.5 \\
\hline Sovereign Wealth Fund & President & Singapore & 320 \\
\hline State Government Treasury & Treasurer & USA & 87 \\
\hline State Pension Fund & Chief Economist & Canada & 132.44 \\
\hline State Employees' Pension Fund & $\mathrm{ClO}$ & USA & 273 \\
\hline State Pension Fund & $\mathrm{ClO}$ & U.S & 13.42 \\
\hline State Pension Fund Total & & & 418.86 \\
\hline Superannuation Fund & CEO & Australia & 25.48 \\
\hline Superannuation Fund & $\mathrm{ClO}$ & Australia & 1.365 \\
\hline Superannuation Fund & Head of Investment Strategy & Australia & 5.642 \\
\hline Superannuation Fund & $\mathrm{ClO}$ & Australia & 12.74 \\
\hline Superannuation Fund & Deputy CEO & Australia & 35.32 \\
\hline Superannuation Fund & Director of Client Relations & Australia & 70 \\
\hline Superannuation Fund Total & & & 150.547 \\
\hline University Endowment & Chief Risk Officer & USA & 1.8 \\
\hline University Endowment & Professor of Finance & USA & 7.7 \\
\hline University Endowment & Research Director & USA & 18.7 \\
\hline University Endowment Total & & & 44.4 \\
\hline World Body & Chief Risk Officer & U.S. & 48.82 \\
\hline Asset Management Firm & Managing Director & U.K & \\
\hline Asset Management Firm & Managing Director & Australia & \\
\hline Investment Consultant & Head of Risk management & U.K & \\
\hline Investment Bank & Strategy Advisor & Switzerland & \\
\hline
\end{tabular}

Table 1: Demographics of the respondents for the research study.

7. Institutional Investors do not consider hedge funds as viable downside protection strategies due to counterparty risks although some strategies may be useful in their opinion.

8. Leading Risk Indicators are used for determining the probabilities of extreme market events.

9. Take no action and weather the storm as a strategy for extreme market conditions

10. Market volatility is a given, long term investors should embrace it and benefit from it.

11. Minimum volatility strategies are considered appropriate for downside protection.

12. Risk based asset allocation helps downside protection, risk parity is one such strategy.
13. Rebalancing in and out of the equity allocation is considered the cheapest downside protection for long-term institutional investors.

14. Some Institutional Investors recommend/have used derivative strategies for tail risk hedging for de-risking where appropriate.

15. Mega funds are better of looking for natural or built-in tail risk hedges.

16. Lax Regulation caused the GFC.

\section{Results and Recommendations}

The analysis and coding of the responses from the crucial decision makers provided a comprehensive approach for developing an optimal method for downside protection pertaining to multi-asset portfolios. The tone, quality and preciseness of the responses clearly indicate that 
the respondents take their business very seriously with regards to their fiduciary responsibilities. Several of the respondents spoke about using options and other derivatives for downside protection, a few of them mentioned studies and analysis with regards to using hedge funds to obtain protection. When it came to implementation of such strategies that involved additional costs with relatively lower probabilities of favourable results they tended to hesitate and rightly so, given the nature of their responsibilities. A majority of them reiterated their strong belief in asset allocation, diversification, in-depth risk analysis, and strong support from stakeholders to pursue their task of fulfilling their fiduciary responsibility and fulfilling the institutions objectives namely meeting liabilities, capital preservation and mitigating or managing risks.

\section{Recommendations concerning risk management}

Most long-term investors propose de-risking by reducing allocation to equities implying emphasis on valuation fundamentals. Focusing on the underlying risks in the assets rather than simple diversification tends to provide a better risk return trade-off. A Risk-driven Portfolio Construction may be the most effective path for investors with multiyear time horizons. A more sophisticated approach and long-term perspective is essential for risk management. Choosing time horizons consistent with the liquidity of the assets in the portfolio is crucial. Using scenario analysis, stress tests and regime-switching volatility models are essential to interpret correctly market conditions.

\section{Recommendations relating to benchmarks}

Some respondents highlighted the principle-agent problem associated with using benchmarks that force relative performance on managers. A profit sharing arrangement, in their opinion, will take away the onus from the board of directors to be shared between the principle (the $\mathrm{BOD}$ ) and the agent (the external manager).

Several respondents recommended avoiding market capitalization weighted indices that tended to increase concentration risks, as the price of stocks trended higher.

\section{Recommendations on hedge funds and derivative usage}

Using hedge funds or tail risk insurance is considered inappropriate by many of the respondents suggesting that they prefer traditional measures to provide downside protection. Most of them consider regular risk monitoring and follow-up actions to be crucial.

\section{Recommendations on equity allocation}

Since almost $90 \%$ of the risk in a multi asset portfolio is attributable to equity allocation, it is obviously expected that the investors minimize this risk. Low volatility strategies aid in reducing this risk by nearly $30 \%$. Hence, using minimum variance strategies for equity allocation helps downside protection.

Rebalancing the equity allocation ensures investment discipline and avoids having to adopt herd behaviour. Long-term investors claim to be better off by adopting countercyclical measures when asset prices are attractively low.

\section{Recommendations on asset liability management}

A clear understanding of the investment horizon makes it easier to manage liquidity and ensures that assets need not be sold to meet cash flow requirements. A precise asset liability management approach leads to the right strategic asset allocation (SAA) which ensures that procyclicality is minimized. Large investors need to carefully manage their investment actions to avoid potential impacts on the capital markets. This is confirmed by more than $94 \%$ of the surveyed respondents.

\section{References}

1. Schroders Investment Managment Ltd (2012) Effective downside Risk Managment: Distingusing between core protection and tail risk strategies Investment Perspectives London UK.

2. Canina L, Figlewski S (2005) Program trading and stock index arbitrage New York.

3. Mahayani A, Balder S (2009) How good are portfolio insurance stratagies? International Acturial Association.

4. Khuman A, Constantinou N (2009) How does cppi perform against the simplest guarantee strategies? Working Paper Finance Discussion Papers.

5. Ahoniemi K (2008) Modeling and frecasting the VIX index.

6. Hyung N, Vries CG (2005) Portfolio diversificaiton effects of downside risk Journal of Financial Economics 3: 107-125.

7. Xiong JX, Idzorek TM (2011) The impact of skewness and fat tails on the asset alloation decision Financial Analysis Journal 67: 23-35

8. Mirza K, Huelin L (2010) Portfolio Optimization in a downside risk framework studenttheses bs Copenhagen Denmark.

9. Ody E (2011) 5 strategies to lower risk Kiplinger Personal Finance Magazine.

10. Papaioannou MG, Joonkyu P, Jukka P, Hoorn H (2013) Pro-cyclical behavior of institutional investors during the recent financial crisis: causes impacts and challenges IMF Working Paper International Monetary Fund.

11. Kjaer KN (2010) Asset and risk management in a post-crisis market Presentation at the CFA Institute Third Annual European Investment Conference Copenhagen Denmark.

12. Ang A, Goetzmann WN, Schaefer SM (2009) Evaluation of active management of the Norwegian government pension fund-global Norway: Norwegian Government Pension Fund-Global.

13. Mason M (2010) Sample size and saturation in phd studies using qualitative interviews Qualitative Social Research.

14. Soderquist KE (2013) Qualitative data analysis Dubai UAE. 